\title{
Decamole Per Liter
}

National Cancer Institute

\section{Source}

National Cancer Institute. Decamole Per Liter. NCI Thesaurus. Code C105483.

A unit of concentration (molarity unit) equal to one decamole of solute in one liter of solution. 